\title{
Structural variations in the complete series of lanthanoid complexes of a calix[4]arene trisamide
}

Gareth L. Nealon, ${ }^{A, B}$ Matthew J. Mclldowie, ${ }^{A}$ Brian W. Skelton, ${ }^{C}$ Mauro Mocerino, ${ }^{A}$ Massimiliano Massi ${ }^{A}$ and Mark I. Ogden ${ }^{A, C}$

ADepartment of Chemistry, Curtin Institute of Functional Molecules and Interfaces, Curtin University, GPO Box U 1987, Perth, Western Australia, 6845, Australia.

${ }^{B}$ Centre for Microscopy, Characterisation and Analysis, The University of Western Australia, Perth, Western Australia 6009, Australia.

'School of Molecular Sciences, M310, The University of Western Australia, Perth, Western Australia 6009, Australia.

Dedication Vale Allan. We miss the man, his kindness, and the scholarly energy he poured into structural chemistry.

\section{Abstract}

Lanthanoid picrate complexes of 5,11,17,23-tetra-tert-butyl-25-hydroxy-26,27,28tris(dieth- ylcarbamoylmethoxy)calix[4]arene $(\mathbf{L H})$ have been synthesised and structurally characterised, to complete this series for all lanthanoids (other than promethium). From cerium to lutetium, three structural types are observed; Type I, $\left[\operatorname{Ln}(\mathbf{L})\left(O, O^{\prime}\right.\right.$-pic $\left.)\right]($ pic $)$, Ln=Ce - Dy; Type II, $\left[\operatorname{Ln}(\mathbf{L})(O\right.$-pic) $]($ pic $), \operatorname{Ln}=$ Tb, Ho; Type III, $[\operatorname{Ln}(\mathbf{L})(\mathrm{HOEt})](\text { pic })_{2}$, $\mathrm{Ln}=\mathrm{Er}-\mathrm{Lu}$. With lanthanum, three different 10-coordinate complexes were characterised; $\left[\mathrm{Ln}(\mathbf{L})\left(O, O^{\prime}\right.\right.$-pic $\left.)(\mathrm{HOEt})\right]($ pic $), \quad\left[\operatorname{Ln}(\mathbf{L})\left(O, O^{\prime}\right.\right.$-pic $\left.)\left(\mathrm{OH}_{2}\right)\right]($ pic $), \quad$ and $\quad\left[\operatorname{Ln}(\mathbf{L})\left(O, O^{\prime}-\right.\right.$ pic)(HOMe)](pic). The crystallization of Type I and II observed for terbium shows that the stability of the different structures are sensitively poised at the transition points. Nevertheless, the structures show that the vacant space in the coordination sphere left by the trisamide $\mathbf{L}$ tends to reduce across the series as expected. It is occupied by a bidentate picrate anion and unidentate solvent molecule with lanthanum, a bidentate picrate anion for cerium to dysprosium (Type I), a unidentate picrate anion for terbium and holmium (Type II), and finally a unidentate solvent molecule from erbium to lutetium (Type III). The coordination number thus reduces from ten to eight across the series. 


\section{Introduction}

The lanthanoids are of interest for applications that exploit their catalytic, magnetic and photophysical properties. ${ }^{[1-5]}$ They are also a fascinating challenge for coordination chemists, with large and variable coordination numbers, and no strong preference towards specific coordination geometries. ${ }^{[6-7]}$ These two drivers of activity in lanthanoid chemistry are closely linked, since the coordination environment of the cation can impact on the properties of interest. $^{[3,8]}$

Coordination numbers in lanthanoid complexes can vary from three to twelve, with eight and nine the most common, depending on the size of the cation and the steric demand of the ligands. ${ }^{[9]}$ The lanthanoid cations decrease in size across the series (the so-called lanthanoid contraction), which often (but not always ${ }^{[10-12]}$ ) results in a change in structure at some point for a specific ligand set, most often associated with a reduction in the coordination number. Changes in the complex structure can be small, such as a change from bidentate to unidentate binding, or loss of a unidentate ligand, ${ }^{[13-15]}$ or more substantial changes in the primary coordination sphere ligands can also occur. ${ }^{[8,16]}$ It is often assumed that a representative structure from the light and heavy lanthanoid elements is sufficient to characterise a series, but more detailed studies have revealed that this assumption can be flawed. ${ }^{[17]}$

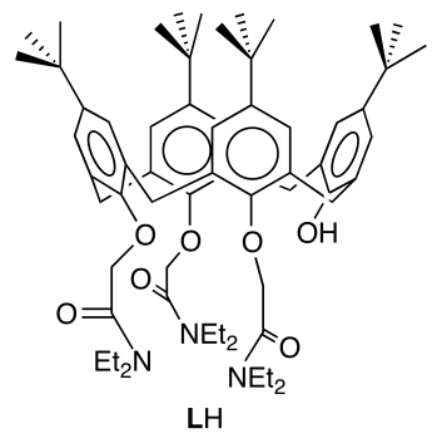

We have incorporated the trisamide calix[4]arene $\mathbf{L}$ as a binding site for lanthanoids in polymeric materials. ${ }^{[18-19]}$ The calixarene also serves as an antenna ligand for the metal ions, producing light-emitting hybrid materials. The aim of using the trisamide, rather than the more well studied tetraamide, ${ }^{[20-27]}$ was to explore the potential of the vacant site in the coordination sphere for sensing purposes, whereby the number of co-ligand(s) and their denticity may impact on the luminescence of the lanthanoid complexes. ${ }^{[18]}$ Our previous studies have shown that the structures of the lanthanoid complexes of $\mathbf{L}$ vary with changes in the lanthanoid ion. ${ }^{[28-29]}$ The vacant coordination site in the readily crystallised picrate salts was found to be occupied by a bidentate picrate anion with the larger lanthanoid 
cations. As the size of the metal ion decreased, the picrate anion was found to bind in a unidentate mode, and then with the heavier lanthanoids, the anion was displaced to the second coordination sphere. To better understand how these complexes change in structure as a consequence of the size of the lanthanoid cation, we have now investigated the structures of the picrate salts across the entire lanthanoid series, in the +3 oxidation state.

\section{Results and Discussion}

The lanthanoid picrate complexes of $\mathbf{L H}$ crystallise readily from dichloromethane/ethanol solvent mixtures, albeit with variable solvation which rendered confirmation of their purity by microanalysis difficult. The discussion therefore focuses on the results of the single crystal x-ray structure determinations, which while variable in quality, are sufficient to accurately describe the nature of the complexes formed. The structures reported previously define three structural types: Type I, $\left[\operatorname{Ln}(\mathbf{L})\left(O, O^{\prime}-\right.\right.$ pic $\left.)\right]($ pic $), \operatorname{Ln}=\mathrm{Sm}, \mathrm{Gd}$; Type II, $[\operatorname{Ln}(\mathbf{L})(O$-pic $)]($ pic $), \operatorname{Ln}=\mathrm{Ho}$; Type III, $[\operatorname{Ln}(\mathbf{L})(\mathrm{HOEt})](\text { pic })_{2}, \mathrm{Ln}=\mathrm{Yb}$. Considering first Type I, an isomorphous series of structures was obtained for lanthanoids ranging from Ce to Dy. The crystal data for the new structures are given in Table 1-3, and the Ln-O bond lengths for the full series are listed in Table 4. The lanthanoid cations in these complexes are 9-coordinate, bound to the seven $\mathrm{O}$ atoms of the calixarene, and a bidentate picrate anion. The unsubstituted calixarene phenolate $\mathrm{O}(11)$ atom makes the closest approach to the $\mathrm{Ln}$ cation in all cases. The amide $\mathrm{O}$ atoms and picrate phenol $\mathrm{O}$ atom are at comparable distances, with longer distances to the phenol ether $\mathrm{O}$ atoms. Consistent with the decrease in the metal ion radius, these $\mathrm{Ln}-\mathrm{O}$ bond lengths generally decrease monotonically across the series. The exception is the nitro- $O$ atom of the bidentate picrate anion, for which the Ln-O distance increases across the series, as has been observed previously in the lanthanoid picrate hydrates. ${ }^{[17]}$ The solvation in this series was variable, and it is interesting to note that even the solvent found in the calixarene cavity varied between an ethanol molecule $(\mathrm{Ln}=\mathrm{Ce}, \mathrm{Nd}, \mathrm{Eu} \mathrm{Gd})$, or a disordered mixture of ethanol and dichloromethane $(\mathrm{Ln}=\mathrm{Pr}, \mathrm{Sm}, \mathrm{Tb}, \mathrm{Dy})$.

In the initial series of crystal growth experiments, no new members of the Type II structure were isolated, to add to the previously reported Ho complex. Instead, new Type III complexes were characterised for $\mathrm{Er}$, $\mathrm{Tm}$ and $\mathrm{Lu}$, isomorphous with the previously reported $\mathrm{Yb}$ complex. These complexes are 8-coordinate, with the picrate anion, now 
positioned in the second coordination sphere, replaced by an ethanol solvent ligand (Figure 1(c)). While the Ln-O lengths again decrease from $\mathrm{Er}$ to $\mathrm{Lu}$, it is interesting to note that the $\mathrm{Tm}$ and $\mathrm{Yb}$ oxygen bond lengths are very similar. In each of these complexes, the calixarene cavity is occupied by an ethanol solvent molecule.

(a)

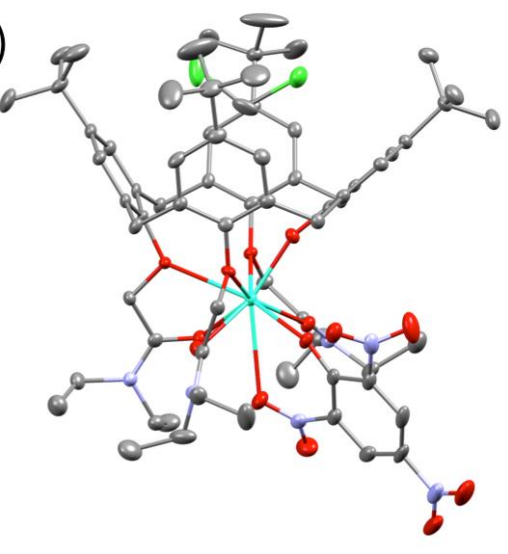

(b)

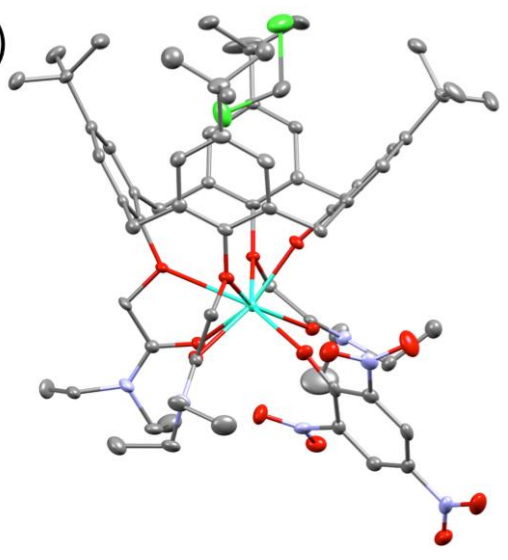

(c)

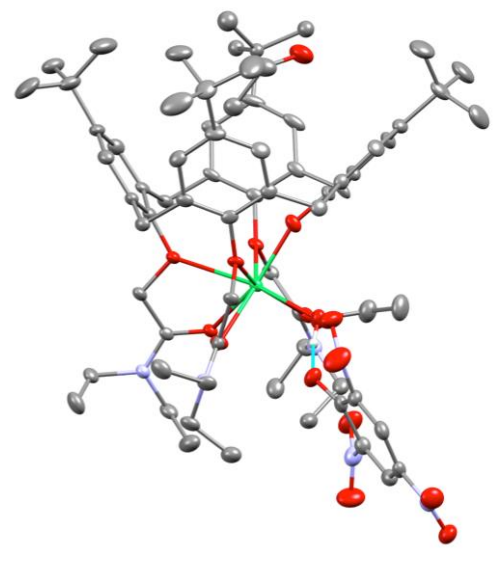

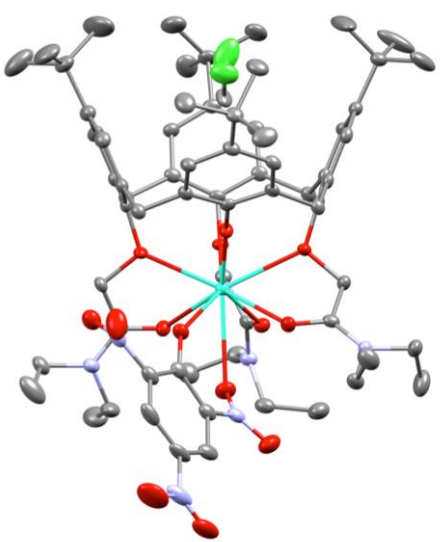
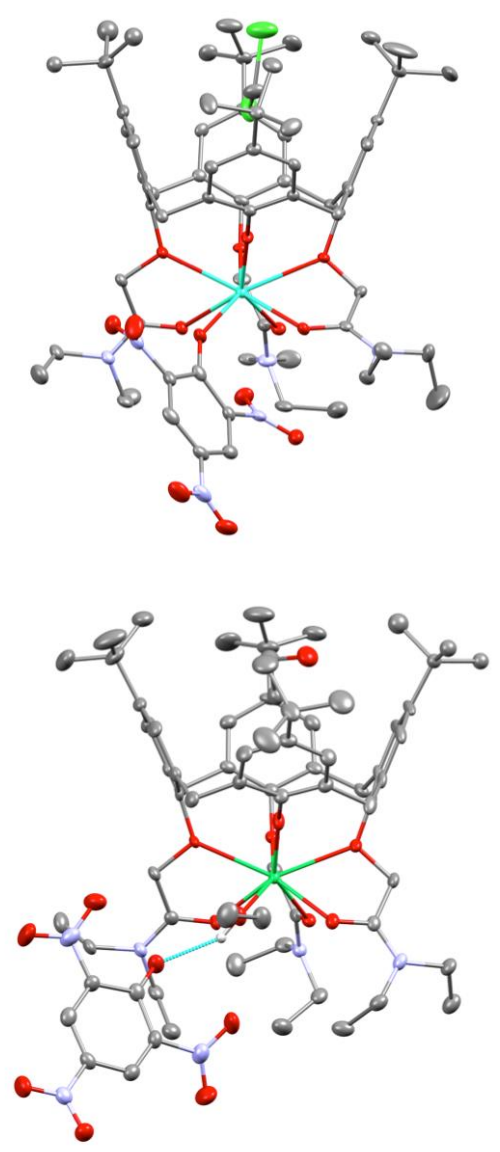

Fig. 1 Two views of the complex cation with included solvent for examples of the three main structural types characterised in the lanthanoid picrate complexes of $\mathbf{L}$; (a) Type I, TbL $\mathbf{L}^{\mathrm{I}}$, (b) Type II, TbL $\mathbf{L}^{\mathrm{II}}$, and (c) Type 3, TmL (inclusive of the picrate anion in the second 
coordination sphere). Hydrogen atoms and minor components of disorder are omitted for clarity. Ellipsoids have been drawn at the 50\% probability level.

At this point, the changes in structure across the lanthanoid series for these complexes appeared well defined. Type I was observed for Ce to Dy, a single example of Type II had been found for Ho, and Type III completed the series for Er to Lu. Upon repeating the synthesis of the $\mathrm{Tb}$ complex on a 10x larger scale, however, two different crystals could be discerned in the precipitate. The orange crystals were confirmed to be the Type I complex, $\mathrm{Tb} \mathbf{L}^{\mathrm{I}}$, already characterised. The less numerous yellow crystals were found to be a new Type II phase, ${ }^{\ddagger}$ isomorphous with the previously reported Ho complex. The two different complex cations are shown in Figure 1(a,b), with the views provided intended to emphasise the similarity between the two complexes. Compared to the HoL Type II complex, the distinction between bidentate or unidentate binding of the coordinated picrate anion in $\mathrm{TbL}^{\mathrm{II}}$ is less clear (see bond lengths in Table 4). Nevertheless, the picrate phenol $\mathrm{O}$ atom distance decreases by $1.6 \%$ in $\mathrm{Tb} \mathbf{L}^{\mathrm{II}}$ compared to $\mathrm{Tb} \mathbf{L}^{\mathrm{I}}$, and the nitro $\mathrm{O}$ atom distance increases by $5 \%$, consistent with unidentate and bidentate binding respectively. Comparing the Ho and Tb Type II complexes, the Ln-O bond lengths consistently decrease from $\mathrm{Tb}$ to $\mathrm{Ho}$ as expected. The calixarene conformation in the two $\mathrm{Tb}$ complexes are slightly different, with the dihedral angles of the aromatic rings $1-4$ relative to the methylene $\mathrm{C} 4$ plane being: $\mathrm{TbL}^{\mathrm{I}}$, $\mathrm{Tb} \mathbf{L}^{\mathrm{II}}$; 67.37(8), 69.03(7); 61.0(1), 63.75(7); 68.4(1), 71.49(8); 37.97(9), 43.34(7) ${ }^{\circ}$. The orientation of the included dichloromethane differs as well, with a chlorine atom more deeply positioned in the cavity in the Type II complex, whereas the carbon atom is oriented into the cavity in the Type I complex. It should also be noted that the Type I included solvent molecule is disordered and is partly occupied by an ethanol solvent molecule. It is possible, therefore, that the crystallisation of the different compounds is associated with the changing solvent composition as dichloromethane evaporates from the mixture.

Finally, we turn to complexes of lanthanum to complete this series. The lanthanum system did not crystallise as readily as the other complexes, and the quality of the crystals was variable. As a result, a methanol/dichloromethane solvent mixture was tested along with the ethanol/dichloromethane mixture used with the other systems. The methanol solvent system deposited dark brown crystals that were stable over time $\left(\mathrm{La}^{\mathrm{MeOH}}\right)$, but diffracted poorly. The ethanol solvent system initially deposited dark brown plate-like crystals $\left(\mathrm{LaL}^{*}\right)$, 
which underwent a solvent-mediated transformation to orange rods $(\mathrm{La} \mathbf{L})$ when left to stand for a number of days.

Considering $\mathrm{La} \mathbf{L}$ first, the results of the structure determination are consistent with the formulation $[\mathrm{La}(\mathbf{L})($ pic $)(\mathrm{HOEt})]($ picrate $) \cdot 3(\mathrm{EtOH})$. There is one molecule of ethanol coordinated to the metal centre plus one picrate anion bonded both through the phenolic oxygen atom and the oxygen atom of a nitro group. Another ethanol molecule is situated in the calixarene cavity (Figure 2(a)).

The La atom is bonded to each of the four phenolic oxygen atoms of the calixarene, the distances to O11 2.217(3) $\AA$, being much shorter than to the other three which lie in the range 2.556(3)-3.003(3) $\AA$ (Table 4). The La is also bound to the three amide $\mathrm{O}$ atoms with La-O distances in the range 2.504(3)-2.545(3) $\AA$. The remainder of the coordination sphere consists of the bidentate picrate anion, and an ethanol molecule, so that the La atom is 10coordinate. As shown in Figure 2(a), the overall structure of the complex is quite similar to other members of the series (Figure 1), with the exception that the larger La atom can accommodate the ethanol solvent molecule in the first coordination sphere. 
(a)
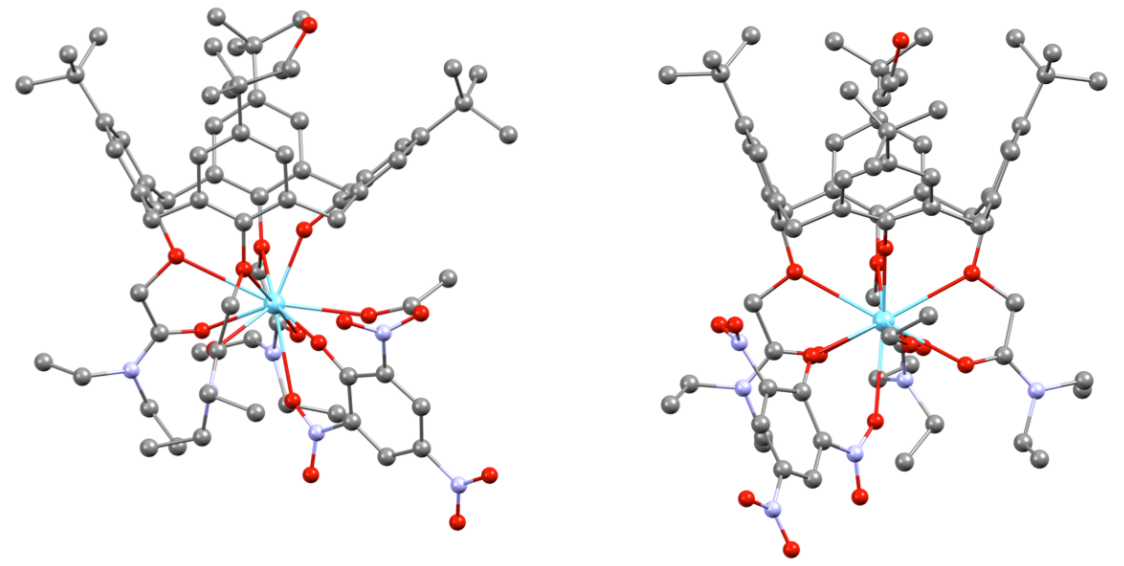

(b)

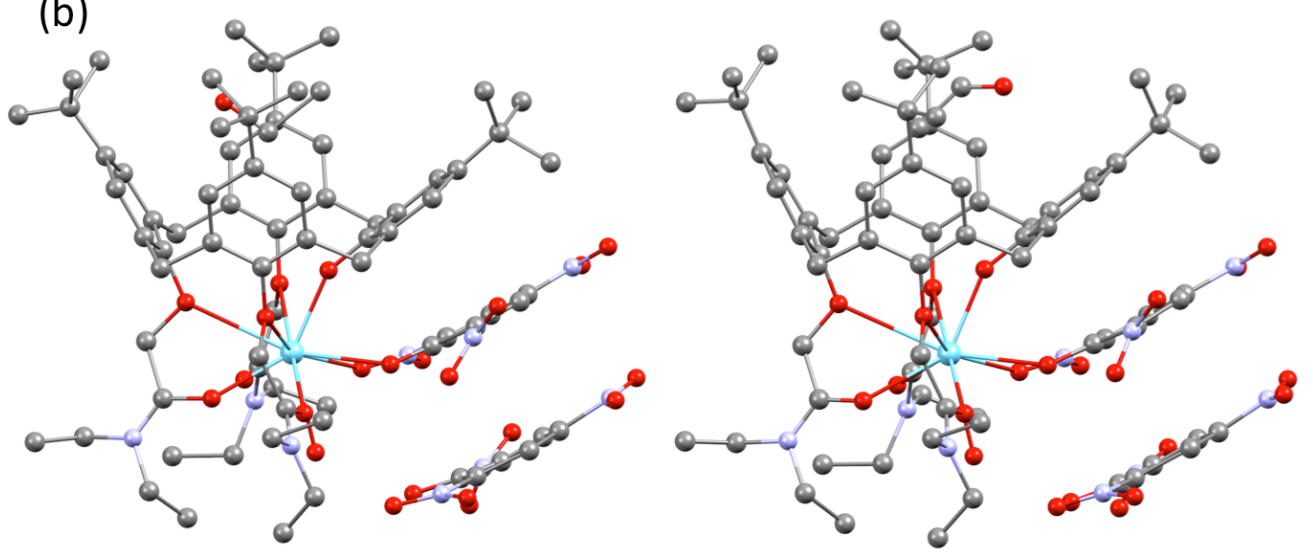

(c)

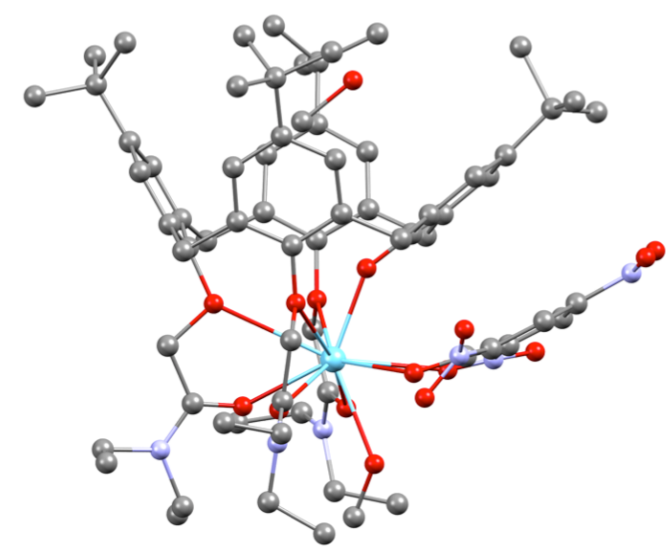

Fig. 2 Ball and stick representations of the lanthanum picrate complex cations of $\mathbf{L}$, with included solvent. (a) Two views of the complex cation of $\mathbf{L a L}$. (b) The two independent complex cations and associated picrate anion in $\mathrm{La}^{*}$. (c) The complex cation of $\mathrm{La} \mathbf{L}^{\mathrm{MeOH}}$. Hydrogen atom and disordered components omitted for clarity.

The structure determination of the initially deposited $\mathrm{La}^{*}$ gave lower quality but clearly defined results. The formulation of this complex is $\left[\mathrm{La}(\mathbf{L})(\right.$ pic $\left.)\left(\mathrm{OH}_{2}\right)\right]($ picrate) $) \cdot 2\left(\mathrm{C}_{2} \mathrm{H}_{5} \mathrm{OH}\right)$. 
There are two independent cations in the unit cell which are virtually identical. The structure consists of a $\mathrm{La}$ atom bonded to each of the four phenolic $\mathrm{O}$ atoms of the calixarene, the distances to O11 (molecule 1) and O61 (molecule 2) 2.262(13) and 2.271(14) $\AA$ being much shorter than to the other three which lie in the range 2.654(14)-2.962(15) $\AA$ similar to those of $\mathrm{LaL}$. The $\mathrm{La}$ atoms are also bound to the three amide $\mathrm{O}$ atoms with La-O distances in the range 2.439(15)-2.539(14) $\AA$. The structure differs from the others in the series in that a molecule of water is included in the coordination sphere, the bond distances being $\mathrm{La} 1-\mathrm{O}(1) 2.633(15)$ and $\mathrm{La} 2-\mathrm{O}(2)$ 2.655(17) $\AA$. Thus the $\mathrm{La}$ atom is again 10-coordinate, but the position of the solvent $\mathrm{O}$ atom and picrate nitro $\mathrm{O}$ atom has swapped (Figure 2(b)). This has resulted in the picrate group being able to form $\pi-\pi$ interactions with the $\mathrm{Ph}$ ring ( $\mathrm{n}$ for molecule 1 and $6 \mathrm{n}$ for molecule 2). The centroid...centroid distances are 3.51 and $3.62 \AA$ for molecule 1 and 2 respectively with the angles between the Ph planes being 11.6(8) and 11.9(7) ${ }^{\circ}$. There are also $\pi-\pi$ interactions between the coordinated and the uncoordinated picrate anions, the centroid to centroid distances being 3.47 and $3.48 \AA$ with the interplanar angles being $0.2(4)$ and $1.6(7)^{\circ}$. While the $\pi-\pi$ interactions have not been observed in other members of this series, similar interactions have been observed in the lanthanoid picrate complexes of the analogous 1,3bisamide substituted calix[4]arene. ${ }^{[30-31]}$ In spite of these differences, the dispositions of the calixarene $\mathrm{Ph}$ rings relative to the psendo-4-fold axis do not differ greatly from those of the other structures in the series with the inter-planar angles between the $\mathrm{Cn} 1$ plane and each of the planes of the four Ph rings being 33.6(6),67.0(6),63.8(6),72.6(6) (molecule 1) and 34.2(6), 65.3(6),66.3(7),70.2(6) (molecule 2).

The structure determination of $\mathrm{La} \mathbf{L}^{\mathrm{MeOH}}$ gave results consistent with a formulation $[\mathrm{La}(\mathbf{L})($ pic) $(\mathrm{HOMe})]($ pic) $\cdot 3(\mathrm{MeOH})$, with one of the methanol molecules positioned in the calixarene cavity. The structure of the complex cation is similar to that observed for LaL*, with the aqua ligand replaced with a methanol molecule (Figure 2(c)). The interplanar angles between the $\mathrm{Cn} 1$ plane and each of the planes of the four $\mathrm{Ph}$ rings of the calixarene are $35.9(2), 71.5(2), 64.6(2), 66.5(2)^{\circ}$. The coordinated picrate ligand is again in a position to form $\pi-\pi$ interactions with phenyl ring 1 , although this is complicated by disorder of the picrate ring. The interplanar angles are 19.5(7) and $21.1(8)^{\circ}$ between the picrate ring components and phenyl ring 1 . The dihedral angle between the two components of the coordinated picrate ligand is $9.6(13)^{\circ}$. The centroid to centroid distances are 3.87 and 3.96 
$\AA$. The free picrate anion (not shown) in this case does not have any interaction with other aromatic rings.

\section{Conclusion}

Lanthanoid picrate complexes of trisamide $\mathbf{L H}$ have now been structurally characterised for all the lanthanoids (except promethium). As expected, the coordination number decreases across the series. The coordination number is ten for three different lanthanum complexes, with the calixarene, a bidentate picrate anion, and a unidentate solvent molecule in the coordination sphere. The two species binding in the gap in the coordination sphere left by the trisamide $\mathbf{L}$ were found to vary by orientation and composition, with the metal-calixarene interaction relatively consistent. From cerium to dysprosium, the coordinated solvent molecule is eliminated and the coordination number reduces to nine. An eight-coordinate species with unidentate picrate was characterised for terbium and holmium, however, suggesting that these nine and eight coordinate structures are of similar stability, at least for terbium and probably dysprosium. From erbium to lutetium, eight-coordination persists, but with the bulky picrate anion replaced in the first coordination sphere by an ethanol solvent molecule. The results show that the size of the lanthanoid cation in tris-substituted calixarene complexes influences the binding of species in the vacant coordination site of the $\operatorname{Ln} \mathbf{L}^{2+}$ cation.

\section{Experimental}

Warning: While no issues were encountered in this work, caution should be exercised when handling picrates.

\section{Synthetic Procedures}

5,11,17,23-Tetra-tert-butyl-25-hydroxy-26,27,28-

tris(diethylcarbamoylmethoxy)calix[4] $\operatorname{arene}^{[32]}(\mathbf{L H})$ and lanthanoid picrate hydrates ${ }^{[17]}$ were prepared as described previously. The metal complexes were crystallised following the literature procedure. ${ }^{[28]}$ Typically, three molar equivalents of the lanthanoid picrate hydrate were added to a solution of $\mathbf{L H}(5 \mu \mathrm{mol})$ in dichloromethane/ethanol (50:50 v/v, $2 \mathrm{~mL}$ ), and the solution was allowed to evaporate until crystals deposited. Carrying out the reaction on a 10x scale with terbium picrate hydrate resulted in the deposition of a mixture of predominantly orange crystals of $\mathrm{Tb}^{\mathrm{I}}$ along with some yellow crystals of $\mathrm{Tb} \mathbf{L}^{\mathrm{II}}$. The yellow crystals were found to maintain crystallinity after isolation from the mother liquor, and structure determinations were carried out on the solvated $\left(T \mathrm{~Tb} \mathbf{L}^{\mathrm{II}}\right)$ and desolvated 
crystals $\left(\operatorname{TbL}^{\mathrm{II}}\right.$ (desolvated)). The reaction with lanthanum picrate hydrate initially deposited brown crystals of $\mathrm{LaL}^{*}$, which transformed on standing to orange crystals of LaL. Both phases were structurally characterised. Substituting methanol for ethanol with lanthanum picrate hydrate gave crystals of $\mathrm{La} \mathbf{L}^{\mathrm{MeOH}}$.

\section{Crystallography}

The crystal data for are summarized in Tables 1-3. Crystallographic data for the structures were collected on an Oxford Diffraction Gemini diffractometer using Mo K $\alpha$ radiation (or $\mathrm{Cu} \mathrm{K} \alpha$ radiation for $\mathrm{Ce} \mathbf{L}, \mathrm{La} \mathbf{L}^{*}, \mathrm{La} \mathbf{L}^{\mathrm{MeOH}}$ ). Following absorption corrections and solution by direct methods, the structures were refined against $F^{2}$ with full-matrix leastsquares using the program SHELXL-2014. ${ }^{[33]}$ Unless otherwise stated, $\mathrm{H}$-atoms were added at calculated positions and refined by use of a riding model with isotropic displacement parameters based on the isotropic displacement parameter of the parent atom. Anisotropic displacement parameters were employed throughout for the nonhydrogen atoms except for those of disordered components, which were refined with isotropic displacement parameters.

\section{Refinement Details}

$\mathrm{Ce} \boldsymbol{L}$ : The solvent was modelled as three molecules of ethanol with the site occupancy of one refined to $0.70(1)$. Some geometries were restrained to ideal values. One tert-butyl group was modelled as being disordered over two sets of sites with occupancies refined to 0.812(13) and its complement. OH hydrogen atoms were not located, nor could reasonable positions be found, for two of the solvent molecules. All remaining hydrogen atoms were added at calculated positions and refined by use of riding models with isotropic displacement parameters based on those of the parent atoms. The solvent in the cavity was modelled as being EtOH. The overall formula is therefore $\left[\mathrm{C}_{68} \mathrm{H}_{90} \mathrm{~N}_{6} \mathrm{O}_{14} \mathrm{Ce}\right]^{+}$, picrate, $2.70\left(\mathrm{C}_{2} \mathrm{H}_{5} \mathrm{OH}\right)$.

$\operatorname{Pr} \boldsymbol{L}$ : Solvent ethanol molecule 1 was modelled as being disordered over two sets of sites (labelled 10n and 40n) with site occupancy factors of the disordered components being constrained to 0.5 after trial refinement. The solvent in the cavity of the calixarene was modelled as being part $\mathrm{CH}_{2} \mathrm{Cl}_{2}$ and part EtOH, site occupancy factor for the two components being set to 0.5 after trial refinement. Meaningful positions for the hydroxyl $\mathrm{H}$ atoms of ethanol molecules could not be found and were therefore omitted from the model. The $\mathrm{C}$ atoms of two methyl group (C24n) are disordered over two sets of sites with 
site occupancy factors refined to $0.841(6)$ and its complement. The overall formula is therefore $\left[\mathrm{C}_{68} \mathrm{H}_{90} \mathrm{~N}_{6} \mathrm{O}_{14} \mathrm{Pr}\right]^{+}$, picrate, ${ }_{1 / 2}\left(\mathrm{CH}_{2} \mathrm{Cl}_{2}\right), 3 / 2\left(\mathrm{C}_{2} \mathrm{H}_{5} \mathrm{OH}\right)$.

$N d \boldsymbol{L}$ : One tert-butyl group and one ethanol solvent molecule were modelled as being disordered over two sets of sites with occupancies refined to $0.818(4)$ and its complement for both groups after trial refinement found no significant difference in the two values. Geometries and displacement parameters of the disordered tert-butyl group were restrained to reasonable values. Sensible positions for the $\mathrm{OH} \mathrm{H}$ atoms of the disordered ethanol molecule were not located. The overall formula is therefore $\left[\mathrm{C}_{68} \mathrm{H}_{90} \mathrm{~N}_{6} \mathrm{O}_{14} \mathrm{Nd}\right]^{+}$, picrate, $3\left(\mathrm{C}_{2} \mathrm{H}_{5} \mathrm{OH}\right)$.

EuL: One tert-butyl group was modelled as being disordered over two sets of sites with occupancies constrained to 0.5 after trial refinement. The site occupancies of two of the solvent ethanol molecules refined to 0.68(2) and 0.85(2). Geometries and displacement parameters of the disordered ethanol molecules were restrained to reasonable values. Sensible positions for the $\mathrm{OH} \mathrm{H}$ atoms ethanol molecule were not located. The overall formula is therefore $\left[\mathrm{C}_{68} \mathrm{H}_{90} \mathrm{EuN}_{6} \mathrm{O}_{14}\right]^{+}$, picrate $-2.53\left(\mathrm{C}_{2} \mathrm{H}_{5} \mathrm{OH}\right)$.

$T b \boldsymbol{L}^{I}$ : The methyl groups of one of the tert-butyl groups were modelled as being disordered over two sets of sites with occupancies refined to $0.829(7)$ and its complement. The solvent molecule in the calix was modelled as a mixture of a $\mathrm{CH}_{2} \mathrm{Cl}_{2}$ and $\mathrm{EtOH}$ molecules, with occupancies refined to 0.704(4) $\left(\mathrm{CH}_{2} \mathrm{Cl}_{2}\right)$ and 1-0.704(4) (EtOH). One of the other solvent molecules was also modelled as being a mixture except with occupancy factors for both components set at 0.5 after trial refinement.

Dy $\boldsymbol{L}$ : The methyl groups of one of the tert-butyl groups were modelled as being disordered over two sets of sites with occupancies refined to 0.754(8) and its complement. Residual electron density near the solvent ethanol molecule in the calix was modelled as a $\mathrm{CH}_{2} \mathrm{Cl}_{2}$ molecule, with occupancies refined to $0.825(1)(\mathrm{EtOH})$ and 1-0.825(1) $\left(\mathrm{CH}_{2} \mathrm{Cl}_{2}\right)$. The site occupancy of another ethanol molecule was refined to 0.664(7).

$\operatorname{Tb} \boldsymbol{L}^{I I}$ : The solvent molecule in the calix was modelled as $\mathrm{CH}_{2} \mathrm{Cl}_{2}$ with occupancies set at unity after trial refinement. The solvents at the other site were modelled as being part $\mathrm{CH}_{2} \mathrm{Cl}_{2}$ and part ethanol on the basis of refinement and possible hydrogen bonding with occupancies refined to $0.751(3)$ and 1-0.751(3) respectively. Geometries of the $\mathrm{CH}_{2} \mathrm{Cl}_{2}$ component were restrained to ideal values. One tert-butyl group and one pendant ethyl groups were also modelled as being disordered with site occupancies fixed at 0.5 after trial refinement. The ethanol hydroxyl hydrogen atom was not located. 
$\operatorname{Tb} \boldsymbol{L}^{I I}$ (desolvated): The site occupancy of the $\mathrm{CH}_{2} \mathrm{Cl}_{2}$ solvent in the calix was refined to $0.125(3)$ with the molecular geometries restrained to ideal values.

$\operatorname{Er} \boldsymbol{L}, \operatorname{TmL}$ and $L u \boldsymbol{L}$ : The hydroxyl hydrogen atom on the solvent ethanol molecule in the calix was not included in the model. The corresponding atom on the coordinated ethanol was located in the difference map and refined with restrained geometries. One tert-butyl group (14n) was modelled as being disordered over two sets of sites with occupancies set at 0.5 after trial refinement.

LaL: Two tert-butyl groups and the solvent ethanol molecules were modelled as being disordered over two sets of sites with geometries and displacement parameters restrained to reasonable values. The atoms of the solvent ethanol molecules were refined with isotropic parameters. The $\mathrm{OH}$ hydrogen atom on the coordinated ethanol was included according to hydrogen bonding considerations. Meaningful positions for the $\mathrm{OH} \mathrm{H}$ atoms on the disordered solvent ethanol molecules could not be found and were therefore omitted from the model.

$L_{a} L^{*}$ : Anisotropic displacement parameters were employed for the La atoms only. Meaningful positions for the $\mathrm{OH} \mathrm{H}$ atoms for ethanol and water molecules could not be found and were therefore omitted from the model. Although the final residuals were rather high, recollection of the data set on another crystal was not possible due to deterioration of the original sample. The overall formula is $\left[\mathrm{C}_{68} \mathrm{H}_{92} \mathrm{LaN}_{6} \mathrm{O}_{15}\right]^{+}$, picrate, $2\left(\mathrm{C}_{2} \mathrm{H}_{5} \mathrm{OH}\right)$. $\mathrm{La}^{\mathrm{MeOH}}$ : The methyl groups of one tert-butyl group are disordered over two sites with refined site occupancy factors 0.671(5) and its complement for the two components. The coordinated picrate ligand was modelled as being disordered over two sites (groups with atom labels $5 \mathrm{n}$ and $7 \mathrm{n}$ ) with equal occupancies and common phenolic oxygen atoms. Their geometries were restrained to ideal values. The $\mathrm{OH}$ groups of the methanol molecules were refined with restrained geometries. 


\section{Footnote}

$\mp \mathrm{It}$ is interesting to note that it was found that $\mathrm{Tb}^{\mathrm{II}}$ maintained crystallinity upon drying such that a structure determination could be performed ( $\operatorname{Tb} \mathbf{L}^{\mathrm{II}}$ (desolvated)). The modelling found no residual electron density where solvent of crystallisation was located in the solvated crystal, aside from residual dichloromethane in the calixarene cavity, with a population that refined to $0.125(3)$. This is unusual for calixarene complexes which more commonly lose crystallinity on removal from the mother liquor. The discussion here focuses on the solvated version of the structure, on the assumption this is a better comparison to draw with the fully solvated Type I $T b \mathbf{L}^{\mathrm{I}}$ structure.

\section{Conflicts of Interest}

The authors declare no conflicts of interest.

\section{References}

[1] N. C. Martinez-Gomez, H. N. Vu, E. Skovran, Inorg. Chem., 2016, 15, 10083-10089.

[2] S. V. Eliseeva, J. C. G. Bunzli, Chem. Soc. Rev., 2010, 39, 189.

[3] D. N. Woodruff, R. E. P. Winpenny, R. A. Layfield, Chem. Rev., 2013, 113, 5110.

[4] E. Debroye, T. N. Parac-Vogt, Chem. Soc. Rev., 2014, 43, 8178.

[5] K. Binnemans, Chem. Rev., 2009, 109, 4283.

[6] S. A. Cotton, in Upconverting Nanomaterials: Perspectives, Synthesis, and Applications, ed. C. Altavilla, CRC Press, Boca Raton, 2016, pp. 1.

[7] S. N. Wang, R. Sun, X. S. Wang, Y. Z. Li, Y. Pan, J. F. Bai, M. Scheer, X. Z. You, CrystEngComm, 2007, 9, 1051.

[8] A. J. Hutchings, F. Habib, R. J. Holmberg, I. Korobkov, M. Murugesu, Inorg. Chem., 2014, 53, 2102.

[9] J. C. G. Bunzli, J. Coord. Chem., 2014, 67, 3706.

[10] P. V. Bernhardt, B. M. Flanagan, M. J. Riley, Aust. J. Chem., 2001, 54, 229.

[11] K. Matsumoto, K. Suzuki, T. Tsukuda, T. Tsubomura, Inorg. Chem., 2010, $49,4717$.

[12] M. Seitz, A. G. Oliver, K. N. Raymond, J. Am. Chem. Soc., 2007, 129, 11153.

[13] D. Aguila, L. A. Barrios, V. Velasco, L. Arnedo, N. Aliaga-Alcalde, M. Menelaou, S. J. Teat, O. Roubeau, F. Luis, G. Aromi, Chem. Eur. J., 2013, 19, 5881.

[14] K. P. Carter, S. J. A. Pope, C. L. Cahill, CrystEngComm, 2014, 16, 1873.

[15] K. P. Carter, C. H. F. Zulato, C. L. Cahill, CrystEngComm, 2014, 16, 10189.

[16] M. I. Saleh, E. Kusrini, H. K. Fun, B. M. Yamin, J. Organomet. Chem., 2008, 693, 2561.

[17] J. M. Harrowfield, W. M. Lu, B. W. Skelton, A. H. White, Aust. J. Chem., 1994, 47, 321.

[18] C. R. Driscoll, B. L. Reid, M. J. Mclldowie, S. Muzzioli, G. L. Nealon, B. W. Skelton, S. Stagni, D. H. Brown, M. Massi, M. I. Ogden, Chem. Commun., 2011, 47, 3876. 
[19] B. W. Ennis, S. Muzzioli, B. L. Reid, D. M. D'Alessio, S. Stagni, D. H. Brown, M. I. Ogden, M. Massi, Dalton Trans., 2013, 42, 6894.

[20] P. D. Beer, M. G. B. Drew, P. B. Leeson, M. I. Ogden, J. Chem. Soc., Dalton Trans., $1995,1273$.

[21] C. R. Driscoll, B. W. Skelton, M. Massi, M. I. Ogden, Supramol. Chem., 2016, 28, 567.

[22] A. Arduini, E. Ghidini, A. Pochini, R. Ungaro, G. D. Andreetti, G. Calestani, F. Ugozzoli, J. Inc. Phenom., 1988, 6, 119.

[23] A. Casnati, G. Cavallo, P. Metrangolo, G. Resnati, F. Ugozzoli, R. Ungaro, Chem. Eur. J., 2009, 15, 7903.

[24] A. Casnati, R. Liantonio, P. Metrangolo, G. Resnati, R. Ungaro, F. Ugozzoli, Angew. Chem. Int. Ed., 2006, 45, 1915.

[25] A. Moser, G. P. A. Yap, C. Detellier, J. Chem. Soc., Dalton Trans., 2002, 428.

[26] N. Muzet, G. Wipff, A. Casnati, L. Domiano, R. Ungaro, F. Ugozzoli, J. Chem. Soc., Perkin Trans. 2, 1996, 1065.

[27] N. J. Wolf, E. M. Georgiev, A. T. Yordanov, B. R. Whittlesey, H. F. Koch, D. M. Roundhill, Polyhedron, 1999, 18, 885.

[28] G. L. Nealon, M. Mocerino, M. I. Ogden, B. W. Skelton, J. Inc. Phenom. Macrocyc. Chem., 2009, 65, 25.

[29] M. I. Ogden, B. W. Skelton, A. H. White, C. R. Chimie, 2005, 8, 181.

[30] P. D. Beer, M. G. B. Drew, A. Grieve, M. I. Ogden, J. Chem. Soc., Dalton Trans., 1995, 3455.

[31] P. D. Beer, M. G. B. Drew, P. B. Leeson, M. I. Ogden, Inorg. Chim. Acta, 1996, 246, 133.

[32] M. I. Ogden, B. W. Skelton, A. H. White, J. Chem. Soc., Dalton Trans., 2001, 3073.

[33] G. M. Sheldrick, Acta Crystallogr. Sect. C, 2015, 71, 3. 
Table 1. Crystal data for the Type I structures

\begin{tabular}{|c|c|c|c|c|c|c|}
\hline & CeL & PrL & $\mathbf{N d L}$ & EuL & $\mathrm{TbL}^{\prime}$ & DyL \\
\hline Empirical formula & $\mathrm{C}_{79.39} \mathrm{H}_{108.18} \mathrm{CeN}_{9} \mathrm{O}_{23.70}$ & $\mathrm{C}_{77.50} \mathrm{H}_{102} \mathrm{ClN}_{9} \mathrm{O}_{22.50} \mathrm{Pr}$ & $\mathrm{C}_{80} \mathrm{H}_{110} \mathrm{~N}_{9} \mathrm{NdO}_{24}$ & $\mathrm{C}_{79.06} \mathrm{H}_{107.14} \mathrm{EuN}_{9} \mathrm{O}_{23.53}$ & $\mathrm{C}_{78.80} \mathrm{H}_{105.20} \mathrm{Cl}_{2.41} \mathrm{~N}_{9} \mathrm{O}_{22.80} \mathrm{~Tb}$ & $\mathrm{C}_{79.16} \mathrm{H}_{107.30} \mathrm{Cl}_{0.35} \mathrm{DyN}_{9} \mathrm{O}_{23.49}$ \\
\hline Formula weight & 1707.92 & 1696.03 & 1726.00 & 1712.03 & 1787.67 & 1735.70 \\
\hline Crystal system & Triclinic & Triclinic & Triclinic & Triclinic & Triclinic & Triclinic \\
\hline space group & $P \overline{1}$ & $P \overline{1}$ & $P \overline{1}$ & $P \overline{1}$ & $P \overline{1}$ & $P \overline{1}$ \\
\hline$T(\mathrm{~K})$ & $100(2)$ & $100(2)$ & $100(2)$ & $180(2)$ & $100(2)$ & $100(2)$ \\
\hline$a(\AA)$ & $12.7600(4)$ & $12.7196(3)$ & $12.7267(7)$ & $12.7710(2)$ & $12.6098(7)$ & $12.6761(4)$ \\
\hline$b(\AA)$ & $14.4359(7)$ & $14.4834(3)$ & $14.4057(10)$ & $14.4890(3)$ & $14.4065(6)$ & $14.4150(3)$ \\
\hline$c(\AA)$ & $24.2033(6)$ & $24.6250(4)$ & $24.1320(15)$ & $24.3381(5)$ & $24.7077(8)$ & $24.3837(10)$ \\
\hline$\alpha\left(^{\circ}\right)$ & $100.908(2)$ & $102.427(2)$ & $101.023(5)$ & $101.521(2)$ & $102.804(3)$ & $101.814(3)$ \\
\hline$B\left({ }^{\circ}\right)$ & $94.604(2)$ & $94.373(2)$ & $94.837(5)$ & $94.9850(10)$ & $95.008(4)$ & $95.273(3)$ \\
\hline$\gamma\left({ }^{\circ}\right)$ & $105.458(2)$ & $105.792(2)$ & $105.421(5)$ & $105.5340(10)$ & $105.887(4)$ & $105.423(2)$ \\
\hline$V\left(\AA^{3}\right)$ & $4179.0(2)$ & $4218.89(15)$ & $4143.4(4)$ & $4204.30(14)$ & $4157.0(3)$ & $4153.2(2)$ \\
\hline$Z$ & 2 & 2 & 2 & 2 & 2 & 2 \\
\hline$\rho\left(\mathrm{g} \mathrm{cm}^{-3}\right)$ & 1.357 & 1.335 & 1.383 & 1.352 & 1.428 & 1.388 \\
\hline$\mu\left(\mathrm{mm}^{-1}\right)$ & 4.87 & 0.685 & 0.707 & 0.824 & 1.007 & 0.990 \\
\hline Max./min. absorption & $0.835,0.603$ & $0.934,0.837$ & $0.911,0.774$ & $0.89 / 0.82$ & $0.947 / 0.906$ & $0.87 / 0.79$ \\
\hline Crystal size (mm) & $0.21 \times 0.06 \times 0.04$ & $0.37 \times 0.27 \times 0.10$ & $0.45 \times 0.32 \times 0.15$ & $0.31 \times 0.27 \times 0.14$ & $0.18 \times 0.10 \times 0.08$ & $0.41 \times 0.24 \times 0.20$ \\
\hline$\theta_{\max }\left({ }^{\circ}\right)$ & 67.08 & 33.53 & 38.00 & 32.70 & 31.89 & 32.00 \\
\hline Reflections collected & 40277 & 51425 & 103222 & 56228 & 49127 & 62753 \\
\hline Independent reflections & 14592 & 29670 & 44748 & 27819 & 26615 & 28827 \\
\hline$R_{\text {int }}$ & 0.054 & 0.050 & 0.065 & 0.044 & 0.0647 & 0.0342 \\
\hline Reflections $(I>2 \sigma(I))$ & 12331 & 21532 & 28396 & 22098 & 17032 & 22668 \\
\hline Data/restraints/parameters & 14592 / 22 / 1081 & 29670 / 79 / 1100 & 44748 / 24 / 1100 & 27819 / 36 / 1062 & 26615 / 104 / 1114 & 28827 / 50 / 1090 \\
\hline G.O.F. $\left(F^{2}\right)$ & 1.024 & 1.034 & 0.913 & 1.160 & 0.870 & 0.972 \\
\hline$R_{1}, w R_{2}[I>2 \sigma(I)]$ & $0.0530,0.1231$ & $0.0612,0.1533$ & $0.0493,0.0959$ & $0.0720,0.1701$ & $0.0544,0.1035$ & $0.0427,0.0953$ \\
\hline$R_{1}, w R_{2}$ [all data] & $0.0667,0.1299$ & $0.0894,0.1625$ & $0.0934,0.1037$ & $0.0928,0.1761$ & $0.0875,0.1091$ & $0.0581,0.0983$ \\
\hline$\Delta \rho(\max , \min )\left(\mathrm{e} . \AA^{-3}\right)$ & $1.60,-1.15$ & $3.03,-1.63$ & $2.16,-1.28$ & $2.07,-3.31$ & $1.78,-1.44$ & $2.04,-1.14$ \\
\hline CCDC No. & 1548372 & 1548373 & 1548374 & 1548375 & 1548376 & 1548377 \\
\hline
\end{tabular}


Table 2. Crystal data for the Type II and III structures

\begin{tabular}{|c|c|c|c|c|c|}
\hline & TbL" & TbL"(desolvated) & ErL & $\mathrm{TmL}$ & LuL \\
\hline Empirical formula & $\mathrm{C}_{76.75} \mathrm{H}_{99} \mathrm{Cl}_{2.50} \mathrm{~N}_{9} \mathrm{O}_{21.75} \mathrm{~Tb}$ & $\mathrm{C}_{74.13} \mathrm{H}_{92.25} \mathrm{Cl}_{0.25} \mathrm{~N}_{9} \mathrm{O}_{21} \mathrm{~Tb}$ & $\mathrm{C}_{78} \mathrm{H}_{104} \mathrm{ErN}_{9} \mathrm{O}_{23}$ & $\mathrm{C}_{78} \mathrm{H}_{104} \mathrm{~N}_{9} \mathrm{O}_{23} \mathrm{Tm}$ & $\mathrm{C}_{78} \mathrm{H}_{104} \mathrm{LuN}_{9} \mathrm{O}_{23}$ \\
\hline Formula weight & 1743.19 & 1613.16 & 1702.96 & 1704.63 & 1710.67 \\
\hline Crystal system & Triclinic & Triclinic & Monoclinic & Monoclinic & Monoclinic \\
\hline space group & $P \overline{1}$ & $P \overline{1}$ & $P 2_{1} / \mathrm{n}$ & $P 2_{1} / \mathrm{n}$ & $P 2_{1} / \mathrm{n}$ \\
\hline$T(\mathrm{~K})$ & $100(2)$ & $100(2)$ & $100(2)$ & $100(2)$ & $100(2)$ \\
\hline$a(\AA)$ & $12.702(5)$ & $12.4131(2)$ & $13.2330(2)$ & $13.2118(4)$ & $13.18680(10)$ \\
\hline$c(\AA)$ & $23.536(5)$ & $23.2527(4)$ & $22.3266(4)$ & $22.3355(8)$ & $22.2772(2)$ \\
\hline$\alpha\left(^{\circ}\right)$ & $72.161(5)$ & $72.919(2)$ & 90 & 90 & 90 \\
\hline$B\left(^{\circ}\right)$ & $80.213(5)$ & $78.180(2)$ & $91.520(2)$ & $91.424(4)$ & $91.7640(10)$ \\
\hline$\gamma\left({ }^{\circ}\right)$ & $89.702(5)$ & $87.857(1)$ & 90 & 90 & 90 \\
\hline$V\left(\AA^{3}\right)$ & $4051(2)$ & $3905.7(1)$ & $8239.3(2)$ & $8195.1(5)$ & $8168.55(11)$ \\
\hline$Z$ & 2 & 2 & 4 & 4 & 4 \\
\hline$\mu\left(\mathrm{mm}^{-1}\right)$ & 1.033 & 0.990 & 1.096 & 1.161 & 1.287 \\
\hline Max.,min. absorption & $0.963,0.744$ & $0.975,0.785$ & $0.881,0.684$ & $0.944,0.910$ & $0.746,0.573$ \\
\hline Crystal size (mm) & $0.36 \times 0.30 \times 0.04$ & $0.30 \times 0.27 \times 0.03$ & $0.46 \times 0.21 \times 0.15$ & $0.22 \times 0.11 \times 0.05$ & $0.54 \times 0.35 \times 0.28$ \\
\hline$\theta_{\max }\left({ }^{\circ}\right)$ & 30.00 & 34.44 & 27.00 & 28.00 & 27.50 \\
\hline Reflections collected & 40802 & 113516 & 78119 & 38143 & 105824 \\
\hline Independent reflections & 23585 & 31405 & 17986 & 19774 & 18698 \\
\hline$R_{\text {int }}$ & 0.049 & 0.047 & 0.043 & 0.0425 & 0.0292 \\
\hline Reflections $(/>2 \sigma(I))$ & 16468 & 27029 & 16966 & 12572 & 17815 \\
\hline Data/restraints/parameters & 23585 / 57 / 1085 & 31405 / 2 / 987 & 17986 / 36 / 1022 & 19774 / 37 / 1022 & 18698 / 49 / 1022 \\
\hline G.O.F. $\left(F^{2}\right)$ & 0.889 & 1.043 & 1.343 & 0.888 & 1.459 \\
\hline$R_{1}, w R_{2}[I>2 \sigma(I)]$ & $0.0448,0.0753$ & $0.0375,0.0754$ & $0.0851,0.1963$ & $0.0464,0.0926$ & $0.0825,0.1827$ \\
\hline$R_{1}, w R_{2}$ [all data] & $0.0715,0.0786$ & $0.0489,0.0795$ & $0.0896,0.1986$ & $0.0845,0.0987$ & $0.0856,0.1837$ \\
\hline$\Delta \rho(\max , \min )\left(\mathrm{e} . \AA^{-3)}\right.$ & $1.48,-1.19$ & $1.14,-0.86$ & $6.35,-2.32$ & $3.79,-1.39$ & $4.23,-2.85$ \\
\hline
\end{tabular}


Table 3. Crystal data for the lanthanum structures

\begin{tabular}{|c|c|c|c|}
\hline & $\mathrm{LaL}^{*}$ & LaL & $\mathrm{LaL}^{\mathrm{MeOH}}$ \\
\hline Empirical formula & $\mathrm{C}_{78} \mathrm{H}_{106} \mathrm{LaN}_{9} \mathrm{O}_{24}$ & $\mathrm{C}_{82} \mathrm{H}_{108} \mathrm{LaN}_{9} \mathrm{O}_{25}$ & $\mathrm{C}_{78} \mathrm{H}_{108} \mathrm{LaN}_{9} \mathrm{O}_{25}$ \\
\hline Formula weight & 1692.63 & 1758.68 & 1710.64 \\
\hline Crystal system & monoclinic & Triclinic & Triclinic \\
\hline space group & Cc & $P \overline{1}$ & $P \overline{1}$ \\
\hline$T(\mathrm{~K})$ & $100(2)$ & $100(2)$ & $200(2)$ \\
\hline$a(\AA ̊)$ & $23.2245(9)$ & $13.0803(5)$ & $13.2848(6)$ \\
\hline$b(\AA ̊)$ & $13.2645(4)$ & $15.0850(8)$ & $14.8019(6)$ \\
\hline$c(\AA)$ & $53.572(3)$ & $24.0507(11)$ & $23.8221(10)$ \\
\hline$\alpha\left(^{\circ}\right)$ & 90 & $95.673(4)$ & $86.619(4$ \\
\hline$B\left({ }^{\circ}\right)$ & $92.110(4)$ & $94.935(4)$ & $81.842(4)$ \\
\hline$\gamma\left({ }^{\circ}\right)$ & 90 & $108.406(4)$ & $65.943(4)$ \\
\hline$V\left(\AA^{3}\right)$ & $16492.3(12)$ & $4446.1(4)$ & $4234.2(3)$ \\
\hline$Z$ & 8 & 2 & 2 \\
\hline$\rho\left(\mathrm{g} \mathrm{cm}^{-3}\right)$ & 1.363 & 1.314 & 1.342 \\
\hline$\mu\left(\mathrm{mm}^{-1}\right)$ & 4.668 & 4.359 & 4.560 \\
\hline Max., min. absorption & $0.815,0.547$ & $0.773,0.579$ & $0.759,0.292$ \\
\hline Crystal size (mm) & $0.18 \times 0.13 \times 0.05$ & $0.24 \times 0.09 \times 0.07$ & $0.42 \times 0.16 \times 0.06$ \\
\hline$\theta_{\max }\left({ }^{\circ}\right)$ & 66.08 & 67.18 & 67.06 \\
\hline Reflections collected & 41352 & 41472 & 35508 \\
\hline Independent reflections & 19601 & 15568 & 14707 \\
\hline$R_{\text {int }}$ & 0.0830 & 0.0435 & 0.043 \\
\hline Reflections $(/>2 \sigma(I))$ & 16246 & 13471 & 13759 \\
\hline Data/restraints/parameters & 19601 / 15 / 944 & 15568 / 111 / 1130 & 14707 / $106 / 1138$ \\
\hline G.O.F. $\left(F^{2}\right)$ & 1.057 & 1.030 & 1.126 \\
\hline$R_{1}, w R_{2}[I>2 \sigma(I)]$ & $0.1138,0.2707$ & $0.0514,0.1350$ & $0.0742,0.1866$ \\
\hline$R_{1}, w R_{2}$ [all data] & $0.1330,0.2880$ & $0.0621,0.1449$ & $0.0781,0.1898$ \\
\hline$\Delta \rho(\max , \min )\left(\mathrm{e} . \AA^{-3)}\right.$ & $4.82,-1.87$ & $1.23,-0.95$ & $2.31,-1.26$ \\
\hline CCDC No. & 1548383 & 1548384 & 1548385 \\
\hline
\end{tabular}


Table 4. Lanthanoid oxygen bond distances for the Type I, II, and III, and LnL complexes.

\begin{tabular}{|c|c|c|c|c|c|c|c|c|c|c|}
\hline & \multicolumn{4}{|c|}{ Calixarene phenol O } & \multicolumn{3}{|c|}{ Calixarene amide $O$} & \multirow{2}{*}{$\begin{array}{c}\text { Pic } \\
\text { phenol O } \\
\text { Ln-O(51) }\end{array}$} & \multirow{2}{*}{$\begin{array}{l}\text { Pic nitro O } \\
\text { Ln-O(521) }\end{array}$} & \multirow{2}{*}{$\begin{array}{c}\text { Solvent O } \\
\operatorname{Ln}-\mathrm{O}(\mathrm{X})\end{array}$} \\
\hline & $\operatorname{Ln}-\mathrm{O}(11)$ & $\operatorname{Ln}-\mathrm{O}(21)$ & $\operatorname{Ln}-\mathrm{O}(31)$ & $\operatorname{Ln}-\mathrm{O}(41)$ & $\operatorname{Ln}-\mathrm{O}(212)$ & $\operatorname{Ln}-\mathrm{O}(312)$ & $\operatorname{Ln}-\mathrm{O}(412)$ & & & \\
\hline LaL & $2.217(2)$ & $2.748(3)$ & $3.003(3)$ & $2.774(3)$ & $2.523(2)$ & $2.545(3)$ & $2.504(3)$ & $2.556(3)$ & $2.726(3)$ & $2.661(3)$ \\
\hline $\mathrm{LaL}^{*} \mathrm{~mol} 1$ & $2.262(13)$ & $2.859(15)$ & $2.943(16)$ & $2.654(14)$ & $2.508(16)$ & $2.439(15)$ & $2.522(16)$ & $2.500(15)$ & $2.694(16)$ & $2.633(15)$ \\
\hline $\mathrm{LaL}^{*}{ }^{\mathrm{mol}} 2$ & $2.271(14)$ & $2.850(15)$ & $2.962(15)$ & $2.684(13)$ & $2.539(14)$ & $2.514(14)$ & $2.512(15)$ & $2.543(15)$ & $2.736(15)$ & $2.645(17)$ \\
\hline $\mathrm{LaL} \mathrm{MeOH}$ & $2.255(4)$ & $2.752(4)$ & $3.058(4)$ & $2.902(4)$ & $2.519(4)$ & $2.537(4)$ & $2.506(4)$ & $2.491(4)$ & $2.790(19)$ & $2.610(4)$ \\
\hline \multicolumn{11}{|l|}{ Type I } \\
\hline LaL & $2.217(2)$ & $2.748(3)$ & $3.003(3)$ & $2.774(3)$ & $2.523(2)$ & $2.545(3)$ & $2.504(3)$ & $2.556(3)$ & $2.726(3)$ & \\
\hline CeL & $2.187(3)$ & $2.627(3)$ & $2.698(3)$ & $2.575(3)$ & $2.502(3)$ & $2.444(3)$ & $2.480(3)$ & $2.474(3)$ & $2.739(3)$ & \\
\hline PrL & $2.176(2)$ & $2.623(2)$ & $2.681(2)$ & $2.560(2)$ & $2.481(2)$ & $2.437(2)$ & $2.482(2)$ & $2.458(2)$ & $2.753(2)$ & \\
\hline $\mathrm{NdL}$ & $2.1685(12)$ & $2.5897(12)$ & $2.6582(11)$ & $2.5401(11)$ & $2.4615(12)$ & $2.4169(12)$ & $2.4539(12)$ & $2.4385(12)$ & $2.7355(14)$ & \\
\hline SmL & $2.148(3)$ & $2.589(2)$ & $2.647(3)$ & $2.516(2)$ & $2.428(3)$ & $2.384(3)$ & $2.428(3)$ & $2.417(3)$ & $2.773(3)$ & \\
\hline EuL & $2.138(3)$ & $2.579(3)$ & $2.638(3)$ & $2.519(3)$ & $2.412(3)$ & $2.377(3)$ & $2.418(3)$ & $2.399(3)$ & $2.803(4)$ & \\
\hline $\mathrm{GdL}^{*}$ & $2.132(3)$ & $2.576(2)$ & $2.618(2)$ & $2.510(3)$ & $2.398(2)$ & $2.369(2)$ & $2.414(3)$ & $2.371(2)$ & $2.799(4)$ & \\
\hline TbL' & $2.119(2)$ & $2.565(2)$ & $2.606(2)$ & $2.490(2)$ & $2.383(2)$ & $2.347(2)$ & $2.379(2)$ & $2.361(2)$ & $2.844(2)$ & \\
\hline DyL & $2.1045(14)$ & $2.5532(15)$ & $2.6004(15)$ & $2.4804(15)$ & $2.3789(16)$ & $2.3381(15)$ & $2.3788(15)$ & $2.3584(15)$ & $2.8713(18)$ & \\
\hline \multicolumn{11}{|l|}{ Type II } \\
\hline TbL" & $2.1176(17)$ & $2.5627(17)$ & $2.6249(18)$ & $2.5180(19)$ & $2.3814(18)$ & $2.3592(18)$ & $2.3869(17)$ & $2.3241(17)$ & $2.996(2)$ & \\
\hline HoL & $2.093(2)$ & $2.535(2)$ & $2.593(2)$ & $2.488(2)$ & $2.342(2)$ & $2.329(2)$ & $2.366(2)$ & $2.291(2)$ & $3.107(2)$ & \\
\hline \multicolumn{11}{|l|}{ Type III } \\
\hline ErL & $2.079(5)$ & $2.489(4)$ & $2.501(4)$ & $2.462(4)$ & $2.309(5)$ & $2.349(4)$ & $2.331(5)$ & - & - & $2.346(3)$ \\
\hline TmL & $2.061(3)$ & $2.479(2)$ & $2.493(2)$ & $2.458(2)$ & $2.279(2)$ & $2.332(2)$ & $2.318(3)$ & - & - & $2.342(3)$ \\
\hline YbL & $2.059(3)$ & $2.490(3)$ & $2.488(3)$ & $2.469(3)$ & $2.289(2)$ & $2.322(3)$ & $2.316(3)$ & - & - & $2.332(3)$ \\
\hline LuL & $2.053(4)$ & $2.467(4)$ & $2.487(4)$ & $2.438(4)$ & $2.275(5)$ & $2.328(4)$ & $2.303(5)$ & - & - & $2.306(5)$ \\
\hline
\end{tabular}

